\title{
Potentially Preventable Spending Among High-Cost Medicare Patients: Implications for Healthcare Delivery
}

\author{
Dhruv Khullar, MD, MPP ${ }^{1,2,3}$ D, Yongkang Zhang, $P h D^{7}$, and Rainu Kaushal, $M D, M P H^{1,2,3,4}$ \\ 'Department of Healthcare Policy and Research, Weill Cornell Medicine, New York, NY, USA; ${ }^{2}$ Department of Medicine, Weill Cornell Medicine, \\ New York, NY, USA; ${ }^{3}$ NewYork-Presbyterian Hospital, New York, NY, USA; ${ }^{4}$ Department of Pediatrics, Weill Cornell Medicine, New York, NY, USA.
}

\begin{abstract}
BACKGROUND: High-cost patients account for a disproportionate share of healthcare spending. The proportion and distribution of potentially preventable spending among subgroups of high-cost patients are largely unknown.
\end{abstract}

OBJECTIVE: To examine the distribution of potentially preventable spending among high-cost Medicare patients overall and potentially preventable spending associated with each high-cost category.

DESIGN: A cross-sectional study. We merged Medicare claims and social determinants of health data to group patients into high-cost categories and quantify potentially preventable spending.

PATIENTS: A total of 556,053 Medicare fee-for-service and dual-eligible beneficiaries with at least one healthcare encounter in the New York metropolitan area in 2014.

MAIN MEASURES: High-cost patients were mapped into 10 non-mutually exclusive categories. The primary outcome was episodic spending associated with preventable ED visits, preventable hospitalizations, and unplanned 30-day readmissions.

KEY RESULTS: Overall, potentially preventable spending accounted for $10.4 \%$ of overall spending in 2014 . Preventable spending accounted for $13.3 \%$ of total spending among high-cost patients and $4.9 \%$ among non-highcost patients $(P<0.001)$. Among high-cost patients, $44.0 \%$ experienced at least one potentially preventable encounter compared with $11.4 \%$ of non-high-cost patients $(P<0.001)$, and high-cost patients accounted for $71.5 \%$ of total preventable spending. High-cost patients had on average $\$ 11,502$ in potentially preventable spending-more than 20 times more than non-high-cost patients (\$510). High-cost patients in the seriously ill, frail, or serious mental illness categories accounted for the highest proportion of potentially preventable spending overall, while end-stage renal disease, serious illness, and opioid use disorder were associated with the highest preventable spending per patient.

CONCLUSION: Potentially preventable spending was concentrated among high-cost patients who were seriously ill, frail, or had a serious mental illness. Interventions targeting these subgroups may be helpful for reducing preventable utilization.

Electronic supplementary material The online version of this article (https://doi.org/10.1007/s11606-020-05691-8) contains supplementary material which is available to authorized users.

Received August 7, 2019

Revised December 8, 2019

Accepted January 29, 2020

Published online February 26, 2020
J Gen Intern Med 35(10):2845-52

DOI: $10.1007 / \mathrm{s} 11606-020-05691-8$

(c) Society of General Internal Medicine 2020

\section{INTRODUCTION}

A small proportion of patients account for the majority of healthcare utilization in the USA. Strategies that focus on improving the efficiency of care for these high-cost patients may have a disproportionate impact on overall healthcare spending. However, health systems hoping to capitalize on this insight require a nuanced understanding of three related questions.

First, who are high-cost patients? It is increasingly clear that high-cost patients are not a homogenous population, but rather a diverse group with widely varying clinical and social needs. ${ }^{1-5}$ Second, what proportion of spending on high-cost patients is potentially preventable? If the type and amount of care received by high-cost patients are largely unchangeable, then programs aimed at reducing spending are unlikely to succeed. By contrast, if a substantial share of preventable spending is concentrated among high-cost patients, then efforts to improve care efficiency may yield substantial savings. Prior work has found conflicting results, but one recent study suggests that more than $70 \%$ of potentially preventable spending for Medicare fee-for-service beneficiaries occurs among high-cost patients. ${ }^{6,7}$ Third, assuming high-cost patients are a heterogeneous group and that some proportion of their spending is potentially preventable, how should we target interventions? Given limited resources, health systems, insurers, and large employers may choose to focus interventions on high-cost subgroups with the highest concentration of preventable spending.

Most previous studies segment high-cost patients into mutually exclusive subgroups that rely exclusively on claims data and do not incorporate measures of social complexity. Our study extends prior work in several ways, with the overarching goal of examining the distribution of potentially preventable spending among high-cost Medicare patients. First, we use a framework with 10 non-mutually categories, recognizing that the circumstances and needs of high-cost patients may fall into multiple groupings. Second, our framework explicitly incorporates mental health conditions, which are known contributors to poor health outcomes and high healthcare spending. ${ }^{8-12}$ Finally, we explore the value of incorporating data on patient neighborhood social conditions, as both medical and social 
complexity are increasingly recognized as drivers of healthcare costs. ${ }^{13,14}$

\section{METHODS}

\section{Overview of the Study Design}

We performed an observational, cross-sectional study to identify spending associated with potentially preventable utilization among Medicare fee-for-service patients, including patients dually eligible for Medicare and Medicaid. We examined the distribution of potentially preventable spending in 10 non-mutually exclusive patient categories that were previously defined using Medicare claims data and neighborhood social risk data. We also estimated the average preventable spending associated with each patient category.

\section{Data/Study Population}

This study included 556,053 Medicare fee-for-service and dual-eligible beneficiaries who had at least one healthcare encounter in the New York City metropolitan area in 2014. Patients were included if they were continuously enrolled in Medicare Parts A and B (even if they did not have any claims). Patients were excluded if (1) they had any Medicare Advantage (MA) enrollment, as we did not have access to their full claims data, or (2) they did not have valid zip codes, which prevented linking to the neighborhood social condition data (Appendix Fig. 1). Similar to prior studies, ${ }^{6,15}$ we excluded patients who died during the study period, as they could not contribute to claims throughout the year. For these patients, we conducted a separate sensitivity analysis.

Our two main data sources included Medicare fee-forservice claims data and community-level social data from the American Community Survey (ACS). ${ }^{16}$ Medicare claims included data from Parts A and B, as well as pharmaceutical claims from Part D. ${ }^{17}$ We used the following files: Carrier, Outpatient, MedPAR for inpatient care, Skilled Nursing Facility (SNF), Home Health Agency (HHA), Hospice, Durable Medical Equipment, Part D Drug Event, and Master Beneficiary Summary. Using neighborhood data from the ACS and following a previously defined algorithm, ${ }^{18,}{ }^{19}$ we created a zip code-level Area Deprivation Index (ADI) to measure patients' social risk. The ADI is a multidimensional composite index measuring neighborhood disadvantage including measures of income, education, employment, poverty, and housing conditions $\mathrm{s}^{20}$ and has been shown to influence healthcare utilization. ${ }^{20-22}$

\section{Patient Categorization}

We applied a patient taxonomy of high-cost patient categories developed through quantitative analyses, literature review, focus group interviews with providers and patients, and input from health policy ${ }^{23,24}$ (Appendix Tables 1 and 2). Many of these categories have previously been used to group high-cost patients and shown to influence healthcare utilization and spending. ${ }^{15,}{ }^{25-30}$ Our taxonomy included 10 categories: (1) seriously ill; (2) multiple chronic conditions(3); single highcost chronic condition (4); single condition with high pharmacy cost (5); end-stage renal disease (ESRD) (6); chronic pain (7); frailty (8); serious mental illness (9); opioid use disorder; and (10) social vulnerability. Categories 1 through 9 were based on patient diagnoses, procedures, utilization, and demographic characteristics. Social vulnerability was defined using the ADI at the zip code level. We excluded multiple chronic conditions (2) from our final analyses because more than $97 \%$ of high-cost patients fell into this category.

\section{Identifying Preventable Utilization}

Consistent with prior literature, ${ }^{6,7}$ we defined three categories of potentially preventable utilization: preventable emergency department (ED) visits, preventable hospitalizations, and unplanned readmissions. To identify potentially preventable ED visits, we used an algorithm created by Billings and colleagues, ${ }^{31}$ which has been used and validated in previous studies. ${ }^{32,}{ }^{33}$ This algorithm classified each ED visit into one of four categories based on discharge diagnosis codes: nonemergent; emergent but primary care treatable; emergent, ED care needed but preventable; emergent, ED care needed; and not preventable. ${ }^{34}$ Consistent with previous studies, ${ }^{34,35}$ we defined an ED visit as preventable if the combined probabilities of "non-emergent," "emergent but primary care treatable," and "emergent, ED care needed but preventable" was $75 \%$ or higher. We included only ED visits that did not result in a hospitalization, as the costs for ED visits resulting in hospitalization were either included in preventable costs for the hospitalization itself (if the hospitalization was deemed preventable) or assumed to be non-preventable (if the hospitalization was deemed necessary).

To identify preventable hospitalizations, we used an algorithm from the Agency for Healthcare Research Quality's Prevention Quality Indicators (PQIs). ${ }^{36}$ The PQIs include a set of measures to identify hospitalizations for ambulatory care-sensitive conditions (ACSCs) that could have been prevented with appropriate outpatient care. Finally, to identify unplanned 30-day readmissions, we used the CMS algorithm for unplanned readmissions for any cause within 30 days of discharge. ${ }^{37}$

\section{Analysis}

We calculated total Medicare spending for each beneficiary in 2014 using standardized costs, which adjust for geographic price differences in payment. ${ }^{38}$ We defined high-cost patients as those in the top decile of costs in 2014. ${ }^{6,15}$ Consistent with previous studies, ${ }^{6}$ we included episodic Medicare costs associated with preventable utilization and all other services delivered to patients within 30 days after a potentially preventable ED visit or hospital admission. For ESRD patients, we excluded costs associated with dialysis (which are generally not preventable). Potentially preventable spending was 
categorized into physician services, outpatient services (including ED visits not resulting in hospitalization), inpatient services (including ED visits resulting in hospitalization), post-acute care services, and durable medical equipment.

We first compared the demographic characteristics and comorbidities between high-cost and non-high-cost patients using $t$ tests and chi-square tests. We then examined the distribution of potentially preventable health spending for non-high-cost, high-cost, and high-cost subgroup patients. We determined the top three overlapping subgroups with the highest concentration of preventable spending. The average potentially preventable spending associated with each highcost subgroup was estimated using a generalized linear model (Appendix 2) with a logit link and assumed a gamma distribution of the dependent variable, which helped address heteroscedasticity and the skewness of cost variables. Our model controlled for patient demographics and other enrollment characteristics, including dual-eligibility, original enrollment reason, Part D coverage, and comorbidities. Finally, we examined the distribution of potentially preventable spending across care settings.

All analyses were performed using SAS 9.4 and STATA MP 14.0 software. The Institutional Review Board at Weill Cornell Medicine approved this study.

\section{RESULTS}

\section{Patient Characteristics}

Our sample included 556,053 fee-for-service and dual-eligible Medicare beneficiaries who were continuously enrolled in Medicare Parts A and B in 2014. The 55,605 patients who accounted for the highest $10 \%$ of spending were defined as high-cost patients. As shown in Table 1, compared with nonhigh-cost patients, high-cost patients were more likely to be younger (72.0 vs. $73.9, P<0.001)$, male $(47.6 \%$ vs. $41.5 \%$, $P<0.001)$, black ( $16.0 \%$ vs. $9.4 \%, P<0.001)$, and have more chronic conditions ( 8.6 vs. $5.4, P<0.001$ ). High-cost patients were more likely to originally qualify for Medicare because of disability or ESRD compared with non-high-cost patients (36.0\% vs. $18.4 \%, P<0.001)$.

We identified 81,645 (14.7\%) patients with some potentially preventable utilization in 2014, including 24,453 high-cost patients and 57,192 non-high-cost patients. Preventable spending accounted for $8.9 \%$ of total health spending among all patients, $13.2 \%$ among high-cost patients, and $4.9 \%$ among non-high-cost patients. High-cost patients accounted for $71.5 \%$ of all preventable spending and were far more likely to have preventable utilization compared with non-high-cost patients (44.0\% vs. $11.4 \%, P<0.001)$. The average preventable spending among high-cost patients was $\$ 11,502$ - more than 20 times higher than non-high-cost patients (\$510) (Table 1).

\section{Preventable Spending Among High-Cost Pa- tients by Patient Category}

Total preventable spending among high-cost patients varied across patient categories (Fig. 1). Patients who were seriously ill, frail, or had a serious mental illness accounted for the highest proportion of preventable spending. For example, despite comprising only $5.3 \%$ of the overall patient population, high-cost patients with serious illness accounted for $55.7 \%$ of total preventable spending. We found a similar concentration of preventable spending among high-cost patients who were frail (4.9\% of all patients representing $48.8 \%$ of total preventable spending).

High-cost patients who fell into more than one category and had substantial potentially preventable spending were most likely to be seriously ill and frail, seriously ill with a mental illness, or frail with a serious mental illness. For example, high-cost patients who were both seriously ill and frail accounted for only $4.0 \%$ of

Table 1 Patient Characteristics and Preventable Spending of High-Cost Vs. Non-High-Cost patients

\begin{tabular}{|c|c|c|c|c|}
\hline & & $\begin{array}{l}\text { High-cost patients } \\
(N=\mathbf{5 5 , 6 0 5 )}\end{array}$ & $\begin{array}{l}\text { Non-high-cost patients } \\
(N=500,448)\end{array}$ & $P$ value \\
\hline Age, mean & & $72.0(66.0,82.0)$ & $73.9(68.0,81.0)$ & $P<0.001$ \\
\hline Male & & $26,461(47.6 \%)$ & $207,623(41.5 \%)$ & $P<0.001$ \\
\hline \multirow{7}{*}{ Race } & Unknown & $668(1.2 \%)$ & $7226(1.4 \%)$ & $P<0.001$ \\
\hline & White & $39,877(71.7 \%)$ & $402,255(80.4 \%)$ & \\
\hline & African American & $8893(16.0 \%)$ & $47,193(9.4 \%)$ & \\
\hline & Other & $1681(3.0 \%)$ & $14,547(2.9 \%)$ & \\
\hline & Asian & $1691(3.0 \%)$ & $12,167(2.4 \%)$ & \\
\hline & Hispanic & $2743(4.9 \%)$ & $16,744(3.4 \%)$ & \\
\hline & North American Native & $52(0.1 \%)$ & $316(0.1 \%)$ & \\
\hline \multirow[t]{2}{*}{ Original reason for Medicare enrollment } & ESRD or disability & $20,030(36.0 \%)$ & $91,940(18.4 \%)$ & $P<0.001$ \\
\hline & Other & $35,575(64.0 \%)$ & $408,508(81.6 \%)$ & \\
\hline Part D prescription coverage & & $48,421(87.1 \%)$ & $385,812(77.1 \%)$ & $P<0.001$ \\
\hline Dual-eligible & & $23,317(41.9 \%)$ & $99,171(19.8 \%)$ & $P<0.001$ \\
\hline Average number of chronic conditions & & $8.6(6.0,11.0)$ & $5.4(4.0,7.0)$ & $P<0.001$ \\
\hline Number of patients with any preventable utilization & & $24,453(44.0 \%)$ & $57,192(11.4 \%)$ & $P<0.001$ \\
\hline Average 2014 preventable spending & & $\$ 11,502(\$ 0, \$ 14,433)$ & $\$ 510(\$ 0, \$ 0)$ & $P<0.001$ \\
\hline
\end{tabular}

Notes: P values indicate the significance of the difference between the high-cost group and non-high-cost group. P values were calculated from $t$ tests for continuous variables and from chi-square tests for categorical variables. Parentheses for age, average number of chronic conditions, and average 2014 Medicare spending indicated interquartile intervals. ESRD, end-stage renal disease 


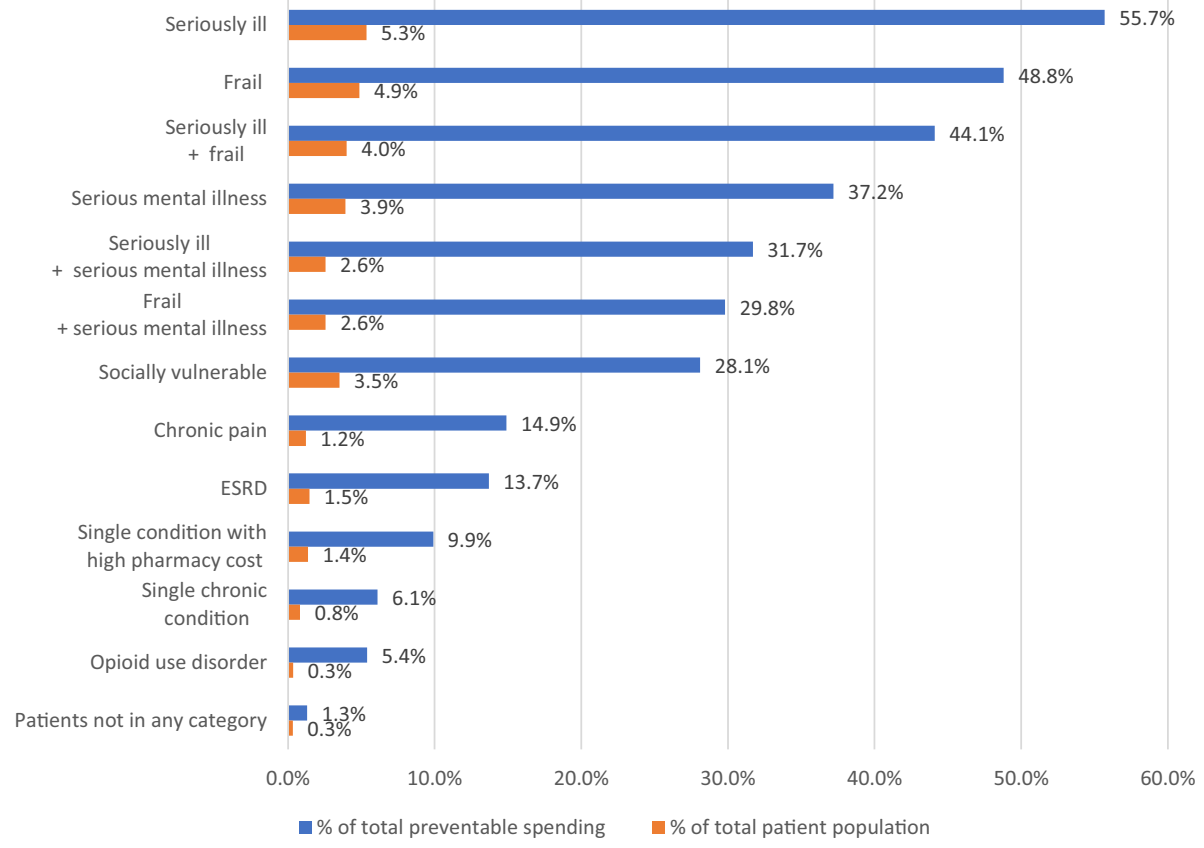

Figure 1 Concentration of preventable spending among high-Cost patient subgroups in 2014 Notes: Subgroups are not mutually exclusive. ESRD, end-stage renal disease.

all patients, but they accounted for $44.1 \%$ of potentially preventable spending. Similarly, while only $2.6 \%$ of all patients were seriously ill and had a serious mental illness, they accounted for $31.7 \%$ of potentially preventable spending.

\section{Average Preventable Spending by High-Cost Patient Categories}

The per-patient preventable spending associated with high-cost categories varied significantly (Fig. 2). The seriously ill category was associated with the highest per-patient preventable spending (\$2633; 95\% confidence interval [CI], \$2318 to \$2948), followed by ESRD (\$1799; 95\% CI, \$1403 to \$2196), opioid use disorder (\$1788; 95\% CI, \$1303 to \$2273), and frailty (\$1215; 95\% CI, \$1031 to \$1400).

\section{Potentially Preventable Spending by Care Settings}

The proportion of potentially preventable spending also varied by care setting (Table 2). More than half of potentially preventable spending for high-cost patients occurred in the inpatient setting with an additional $33.3 \%$ due to physician services and

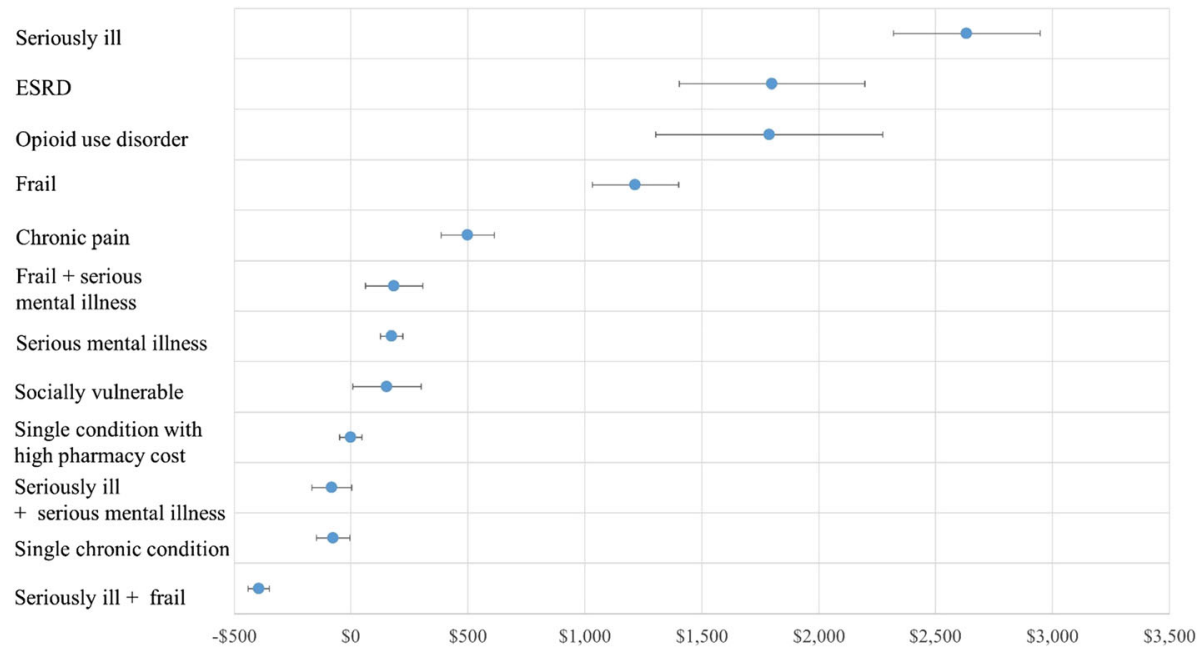

Figure 2 spending associated with high-cost patient categories and 95\% confidence interval in 2014. Notes: Results were derived from a generalized linear regression of preventable spending on indicators for each high-cost category. Regression was adjusted for patient age, gender, race/ethnicity, original enrollment reason, dual-eligible status, Part D enrollment, and number of chronic conditions. ESRD, end-stage renal disease. 
Table 2 Average Potentially Preventable Spending Among HighCost and Non-High-Cost Patients by Care Setting

\begin{tabular}{|c|c|c|}
\hline Care settings & $\begin{array}{l}\text { High-cost } \\
\text { patients }\end{array}$ & $\begin{array}{l}\text { Non-high-cost } \\
\text { patients }\end{array}$ \\
\hline Inpatient & $\$ 6662(57.9 \%)$ & $\$ 226(44.2 \%)$ \\
\hline Physician & $\$ 2526(22.0 \%)$ & $\$ 152(29.7 \%)$ \\
\hline Skilled nursing facility & $\$ 1292(11.2 \%)$ & $\$ 23(4.6 \%)$ \\
\hline Outpatient & $\$ 865(7.5 \%)$ & $\$ 98(19.1 \%)$ \\
\hline Home Health & $\$ 64(0.6 \%)$ & $\$ 8(1.5 \%)$ \\
\hline $\begin{array}{l}\text { Durable medical } \\
\text { equipment }\end{array}$ & $\$ 83(0.7 \%)$ & $\$ 4(0.8 \%)$ \\
\hline Hospice & $\$ 11(0.1 \%)$ & $\$ 0(0.0 \%)$ \\
\hline Total & $\$ 11,502$ & $\$ 510$ \\
\hline
\end{tabular}

skilled nursing facility (SNF) costs. By contrast, outpatient services, home health services, hospice care, and durable medical equipment accounted for a relatively small proportion of potentially preventable spending among high-cost patients.

While the pattern of potentially preventable spending across care settings varied for different high-cost categories, preventable inpatient care dominated all high-cost categories (Fig. 3). High-cost patients who were frail, who were both frail and had a serious medical illness, or who were both frail and had a serious mental illness experienced a relatively large proportion of potentially preventable spending due to SNF costs. Patients with opioid use disorder or a single high-cost chronic condition experienced relatively high potentially preventable spending on outpatient services.

\section{Sensitivity Analysis for Deceased Patients}

We conducted a sensitivity analysis for patients who died during the study period (Appendix Tables 3 and 4, Figs. 7, $8,9,10,11,12$ and 13). Compared with those with 12- month enrollment, patients who died during the study period were more likely to be seriously ill, frail, or have a serious mental illness. Overall, a higher proportion of deceased patients had preventable spending, especially among high-cost deceased patients (Appendix Fig. 8). High-cost deceased patients accounted for $40 \%$ of preventable spending (Appendix Fig. 9). Preventable spending was less highly concentrated in each category compared to patients who did not die during the study period (Appendix Fig. 10). The distribution of preventable spending across care settings was similar to other patients.

\section{DISCUSSION}

In this study, we applied a non-mutually exclusive patient categorization algorithm to identify subgroups of high-cost Medicare fee-for-service patients. We examined how potentially preventable spending varied across these subgroups and how preventable spending differed for high-cost patients versus non-high-cost patients. We find that $10.4 \%$ of overall spending was potentially preventable. This spending was disproportionately concentrated among high-cost patients who, despite comprising only $10 \%$ of the population, accounted for more than $70 \%$ of potentially preventable spending and were four times as likely to have had such spending compared with non-high-cost patients. The average potentially preventable spending for high-cost patients was $\$ 11,534$ in 2014, compared to $\$ 510$ for non-high-cost patients.

We found substantial overlap among patient categories suggesting that many high-cost patients have high levels of medical, behavioral, and social complexity. Potentially

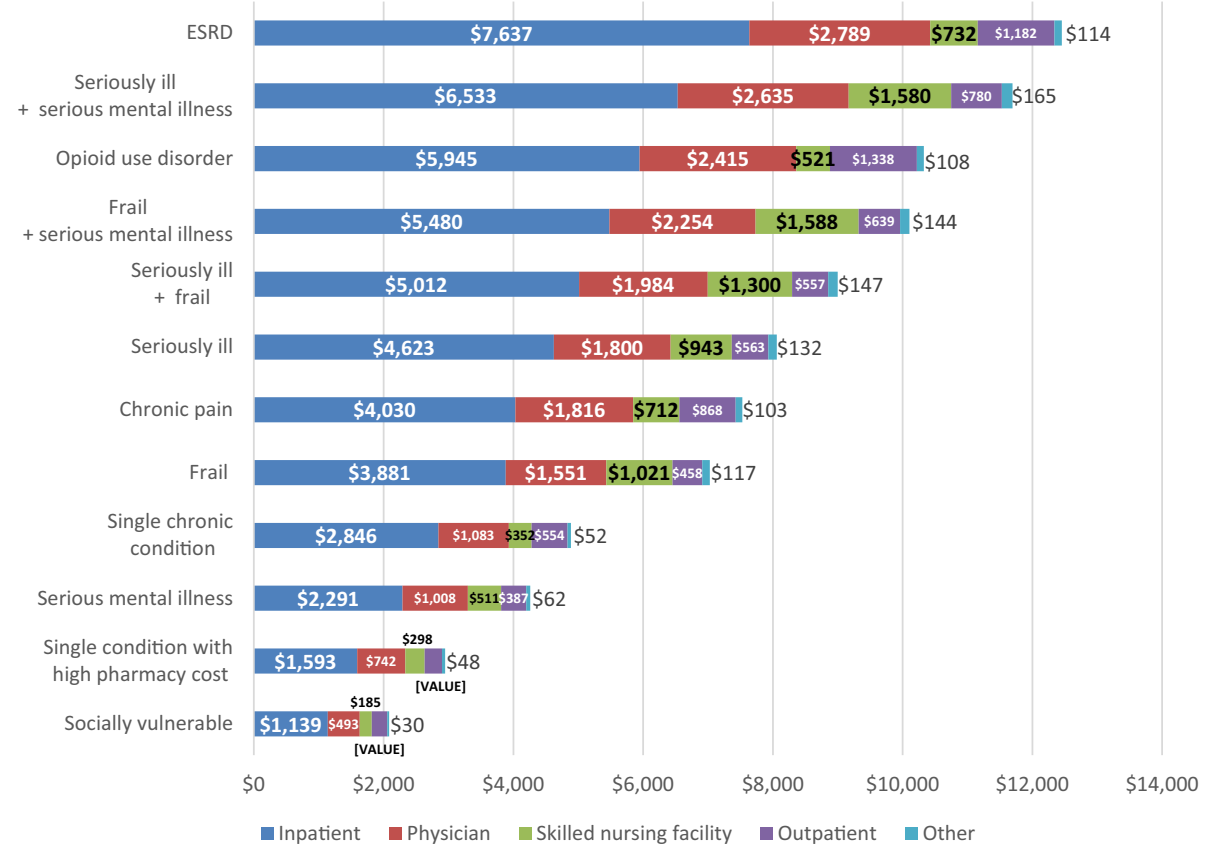

Fig. 3 Potentially preventable spending by high-cost patient category and care setting. Notes: Other includes home health, durable medical equipment, and hospice. Differences in total preventable costs between two consecutive categories are statistically significant $(P<0.001)$. ESRD, end-stage renal disease 
preventable spending was highly concentrated in several overlapping categories, including patients with serious illness, frailty, and serious mental illness. Health systems and payers seeking to reduce preventable spending would do well to focus on these patient subgroups.

Certain categories accounted for a relatively small proportion of overall preventable spending, but were associated with very high per-patient preventable spending. These may be important subgroups to focus on for health systems serving high proportions of such patients. For example, ESRD and opioid use disorder - while relatively uncommon in the overall Medicare population -were associated with large amounts of preventable spending for the individuals with these conditions.

Finally, potentially preventable spending was unevenly spread not only across high-cost subgroups but also across healthcare settings. More than half of potentially preventable spending was due to preventable inpatient care, with preventable physician services and SNF care contributing a large share of the remainder.

A growing body of research has focused on better understanding high-cost Medicare patients. For example, Powers et al. segmented Medicare Advantage (MA) patients into 10 high-cost groups to understand their utilization patterns, finding that $10 \%$ of patients accounted for $55 \%$ of MA spending. ${ }^{3}$ Figueroa et al. recently examined the persistence of high-cost Medicare fee-for-service patients, a finding that $28 \%$ of highcost patients remain high-cost in the following 2 years. ${ }^{5}$ Other studies, like ours, have focused specifically on preventable utilization. For example, Figueroa et al. segmented patients into 6 mutually exclusive claims-based groups and found that $4.8 \%$ of Medicare spending was potentially preventable in 2012 and that high-cost patients accounted for nearly threequarters of such spending. ${ }^{6}$ Our study finds slightly higher rates of preventable spending in $2014(10.4 \%)$ with a similar proportion attributable to high-cost patients.

Our study also differs from prior research in several ways. Many previous studies segmented patients into fewer, mutually exclusive categories, while we introduce a framework with 10 clinically actionable, non-mutual subgroups. This recognizes that high-cost patients often have various clinically meaningful characteristics (e.g., serious mental illness and frailty) requiring different interventions. We also incorporate social risk, which many prior studies do not.

Identifying actionable high-cost subgroups may provide health systems with an opportunity to develop targeted interventions and potentially reduce preventable utilization. For example, comprehensive home-care programs with physical therapy have been shown to maintain functional status in frail elderly individuals and lower the risk of hospitalization. ${ }^{39,} 40$ Recent RCTs have shown that robust care coordination programs can improve quality of life and reduce acute care utilization among frail, older, and low-income patients. ${ }^{41-43}$ Similarly, establishing tailored interdisciplinary transitional care programs for patients with chronic diseases has been shown to reduce unnecessary readmissions. ${ }^{44}$ For seriously ill patients, timely palliative care may improve outcomes and reduce hospital costs, ${ }^{45-47}$ and while dedicated chronic disease management programs for patients with serious mental illness remain rare, they can be effective. ${ }^{48}$ Finally, some interventions may require health systems to partner with local governments and community organizations, particularly to meet the needs of socially vulnerable patients. ${ }^{49-53}$ More research is needed to rigorously examine which interventions most effectively manage high-cost patients, especially as health systems increasingly engage in value-based care.

Our study has limitations. Firstly, although we used validated algorithms to identify potentially preventable spending, it is possible that not all of this spending is in fact preventable, and it is likely that some of this spending is outside the control of the healthcare system. For example, a patient with unstable housing prescribed insulin may re-present to the hospital with hyperglycemia if he no longer has a refrigerator to store his medication; such utilization is unlikely to be preventable by health systems. Secondly, because the use of hospital care triggered our identification of "potentially preventable utilization," the proportion of identified preventable utilization may be skewed toward inpatient services. This bias may however be counterbalanced by the fact that not all the outpatient care in the 30 days following a trigger event was likely preventable, but was counted as such. Thirdly, we excluded patients who died during the study period for our primary analysis (though they were included in a sensitivity analysis). Fourthly, similar to other studies, ${ }^{4,5,15}$ we used claims data for most of our analyses which may not fully capture clinical risk. Moreover, for dually eligible patients, we had access to Medicare claims, but not Medicaid claims, and thus may have underestimated their overall spending. Fifthly, while our dataset includes a diverse group of Medicare beneficiaries in the New York area, patients in other regions of the country may differ from our population. Finally, our analysis was limited to Medicare feefor-service and dually-eligible beneficiaries; it is not clear whether these findings apply to Medicaid or Medicare Advantage beneficiaries or to commercially insured populations.

Nonetheless, this study deepens our understanding of the diversity, needs, and utilization patterns of high-cost patients. We find substantial variation in potentially preventable spending across high-cost subgroups, with a large proportion of spending concentrated among patients with serious medical illness, frailty, and serious mental illness. Conditions such as ESRD and opioid use disorder-while affecting a relatively small proportion of Medicare beneficiaries - are associated with high levels of per-patient preventable utilization. Inpatient care and, to a lesser extent, physician services and SNF care were major drivers of preventable spending. Payers and health systems hoping to more efficiently care for high-cost patients may find it useful to concentrate their efforts in these areas.

Corresponding Author: Dhruv Khullar, MD, MPP; Department of Healthcare Policy and Research, Weill Cornell Medicine, New York, NY, USA (e-mail: Khd9010@med.cornell.edu). 
Funding Information This study was funded by grant PCORI/HSD 1604-35187 ("Identifying and Predicting Patients with Preventable High Utilization") from The Patient-Centered Outcomes Research Institute.

\section{Compliance with Ethical Standards:}

The Institutional Review Board at Weill Cornell Medicine approved this study.

Conflict of Interest: The authors declare that they do not have a conflict of interest.

\section{REFERENCES}

1. Anderson GF, Ballreich J, Bleich S, Boyd C, DuGoff E, Leff B, et al. Attributes common to programs that successfully treat high-need, highcost individuals. Am J Manag Care. 2015;21(11):e597-600.

2. Berry LL, Rock BL, Smith Houskamp B, Brueggeman J, Tucker L. Care coordination for patients with complex health profiles in inpatient and outpatient settings. Mayo Clin Proc. 2013;88(2):184-94.

3. Powers BW, Yan J, Zhu J, Linn KA, Jain SH, Kowalski JL, et al. Subgroups of High-Cost Medicare Advantage Patients: an Observational Study. J Gen Intern Med. 2019;34(2):218-25.

4. Figueroa JF, Lyon Z, Zhou X, Grabowski DC, Jha AK. Persistence and Drivers of High-Cost Status Among Dual-Eligible Medicare and Medicaid Beneficiaries: An Observational Study. Ann Intern Med. 2018;169(8):528-34.

5. Figueroa JF, Zhou X, Jha AK. Characteristics And Spending Patterns Of Persistently High-Cost Medicare Patients. Health Aff (Millwood). 2019;38(1):107-14

6. Figueroa JF, Joynt Maddox KE, Beaulieu N, Wild RC, Jha AK. Concentration of Potentially Preventable Spending Among High-Cost Medicare Subpopulations: An Observational Study. Ann Intern Med. 2017;167(10):706-13.

7. Joynt KE, Gawande AA, Orav EJ, Jha AK. Contribution of preventable acute care spending to total spending for high-cost Medicare patients. JAMA. 2013;309(24):2572-8.

8. Colton CW, Manderscheid RW. Congruencies in increased mortality rates, years of potential life lost, and causes of death among public mental health clients in eight states. Prev Chronic Dis. 2006;3(2):A42.

9. Kisely S, Crowe E, Lawrence D. Cancer-related mortality in people with mental illness. JAMA Psychiatry. 2013;70(2):209-17.

10. Rosenbaum L. Closing the Mortality Gap - Mental Illness and Medical Care. N Engl J Med. 2016;375(16):1585-9.

11. Frayne SM, Halanych JH, Miller DR, Wang F, Lin H, Pogach L, et al. Disparities in diabetes care: impact of mental illness. Arch Intern Med. 2005; 165(22):2631-8

12. Magnan, S. 2017. Social Determinants of Health 101 for Health Care: Five Plus Five. NAM Perspectives. Discussion Paper, National Academy of Medicine, Washington, DC. https://doi.org/10.31478/201710c.

13. Marmot M. Social determinants of health inequalities. Lancet. 2005;365(9464): 1099-104

14. National Academies of Sciences, Engineering, and Medicine. 2017 Accounting for social risk factors in Medicare payment. Washington, DC: The National Academies Press. https://doi.org/10.17226/23635.

15. Joynt KE, Figueroa JF, Beaulieu N, Wild RC, Orav EJ, Jha AK. Segmenting high-cost Medicare patients into potentially actionable cohorts. Healthe (Amst). 2017;5(1-2):62-7.

16. U.S. Census Bureau 2019;Pages American Community Survey (ACS) on $11 / 112019$.

17. Research Data Assistance Center 2019;Pages https://www.resdac.org/ file-availability on 11/11 2019.

18. Hu J, Kind AJH, Nerenz D. Area Deprivation Index Predicts Readmission Risk at an Urban Teaching Hospital. Am J Med Qual. 2018;33(5):493-501.

19. Kind AJ, Jencks S, Brock J, Yu M, Bartels C, Ehlenbach W, et al. Neighborhood socioeconomic disadvantage and 30-day rehospitalization: a retrospective cohort study. Ann Intern Med. 2014;161(11):765-74.

20. Kirby JB, Kaneda T. Neighborhood socioeconomic disadvantage and access to health care. J Health Soc Behav. 2005;46(1):15-31.
21. Knighton AJ, Savitz L, Belnap T, Stephenson B, VanDerslice J. Introduction of an Area Deprivation Index Measuring Patient Socioeconomic Status in an Integrated Health System: Implications for Population Health. EGEMS (Wash DC). 2016;4(3): 1238.

22. Tuliani TA, Shenoy M, Parikh M, Jutzy K, Hilliard A. Impact of Area Deprivation Index on Coronary Stent Utilization in a Medicare Nationwide Cohort. Popul Health Manag. 2017;20(4):329-34.

23. Zhang Y, Zachary G, Khullar D, Unruh MA, Shenkman E, Cohen A Kaushal R. Developing an actionable patient taxonomy to understand and characterize high-cost Medicare patients. Healthcare. https://doi. org/10.1016/j.hjdsi.2019.100406

24. Das LT, Abramson EL, Kaushal R. High-Need, High-Cost Patients Offer Solutions for Improving Their Care and Reducing Costs. NEJM Catal. 2019 https://catalyst.nejm.org/high-need-high-cost-patients-solutions/ Accessed 5 Feb 2019.

25. Long P, Abrams M, Milstein A, Anderson G, Apton KL, Dahlberg MJ. Effective Care for High-Need Patients. National Academy of Medicine Washington, DC; 2017.

26. Tian TY, Zlateva I, Anderson DR. Using electronic health records data to identify patients with chronic pain in a primary care setting. J Am Med Inform Assoc. 2013;20(e2):e275-80.

27. Kim DH, Schneeweiss S. Measuring frailty using claims data for pharmacoepidemiologic studies of mortality in older adults: evidence and recommendations. Pharmacoepidemiol Drug Saf. 2014;23(9):891901

28. Weissman DE, Meier DE. Identifying patients in need of a palliative care assessment in the hospital setting: a consensus report from the Center to Advance Palliative Care. J Palliat Med. 2011;14(1):17-23.

29. Chronic Conditions Data Warehouse. 2018;Pages https://www.ccwdata. org/web/guest/condition-categories on 11/01 2018.

30. Powers BW, Chaguturu SK. ACOs and High-Cost Patients. N Engl J Med. 2016;374(3):203-5.

31. Billings J, Parikh N, Mijanovich T. Emergency department use in New York City: a substitute for primary care? Issue Brief (Commonw Fund). 2000 Nov;(433): 1-5.

32. NYU Wagner. 2017;Pages https://wagner.nyu.edu/faculty/billings/ nyued-background on 01/31 2018.

33. Ballard DW, Price M, Fung V, Brand R, Reed ME, Fireman B, et al. Validation of an algorithm for categorizing the severity of hospital emergency department visits. Med Care. 2010;48(1):58-63.

34. Hwang W, Liao K, Griffin L, Foley KL. Do free clinics reduce unnecessary emergency department visits? The Virginian experience. J Health Care Poor Underserved. 2012;23(3):1189-204.

35. Chen BK, Hibbert $\mathbf{J}$, Cheng $\mathbf{x}$, Bennett $\mathbf{K}$. Travel distance and sociodemographic correlates of potentially avoidable emergency department visits in California, 2006-2010: an observational study. Int J Equity Health. 2015; 14:30.

36. Agency for Healthcare Research and Quality. 2016;Pages https://www. qualityindicators.ahrq.gov/Modules/PQI_TechSpec_ICD09_v60.aspx on 07/01 2017.

37. Centers for Medicare and Medicaid Services. 2015;Pages https://www. cms.gov/Medicare/Medicare-Fee-for-Service-Payment / PhysicianFeedbackProgram/Downloads/2015-ACR-MIF.pdf on 10/08 2018.

38. Pesko MF, Ryan AM, Shortell SM, Copeland KR, Ramsay PP, Sun X, et al. Spending per Medicare Beneficiary Is Higher in Hospital-Owned Small- and Medium-Sized Physician Practices. Health Serv Res. 2017.

39. Gill TM, Baker DI, Gottschalk M, Peduzzi PN, Allore H, Byers A. A program to prevent functional decline in physically frail, elderly persons who live at home. N Engl J Med. 2002;347(14):1068-74

40. Landi F, Onder G, Russo A, Tabaccanti S, Rollo R, Federici S, et al. A new model of integrated home care for the elderly: impact on hospital use. J Clin Epidemiol. 2001;54(9):968-70.

41. Coleman EA, Parry C, Chalmers S, Min SJ. The care transitions intervention: results of a randomized controlled trial. Arch Intern Med. 2006;166(17):1822-8.

42. Counsell SR, Callahan CM, Clark DO, Tu W, Buttar AB, Stump TE, et al. Geriatric care management for low-income seniors: a randomized controlled trial. JAMA. 2007;298(22):2623-33.

43. Marek KD, Stetzer F, Adams SJ, Bub LD, Schlidt A, Colorafi KJ. Cost analysis of a home-based nurse care coordination program. J Am Geriatr Soc. 2014;62(12):2369-76.

44. Miller A, Edenfield EE, Roberto J, Erb JKJHHCM, Practice. Reduction in Re-Hospitalization Rates Utilizing Physical Therapists Within a PostAcute Transitional Care Program for Home Care Patients With Heart Failure. Home Health Care Management \& Practice, 2017;29(1):7-12. 
45. May P, Normand C, Cassel JB, Del Fabbro E, Fine RL, Menz R, et al Economics of Palliative Care for Hospitalized Adults With Serious Illness: A Meta-analysis. JAMA Intern Med. 2018;178(6):820-9.

46. Kelley AS, Morrison RS. Palliative Care for the Seriously Ill. N Engl J Med. 2015;373(8):747-55

47. Rogers JG, Patel CB, Mentz RJ, Granger BB, Steinhauser KE, Fiuzat M, et al. Palliative Care in Heart Failure: The PAL-HF Randomized, Controlled Clinical Trial. J Am Coll Cardiol. 2017;70(3):331-41.

48. Daumit GL, Dickerson FB, Wang NY, Dalcin A, Jerome GJ, Anderson CA, et al. A behavioral weight-loss intervention in persons with serious mental illness. N Engl J Med. 2013;368(17):1594-602.

49. Sandel M, Desmond M. Investing in Housing for Health Improves Both Mission and Margin. JAMA. 2017;318(23):2291-2.

50. Doran KM, Misa EJ, Shah NR. Housing as health care-New York's boundary-crossing experiment. N Engl J Med. 2013;369(25):2374-7.

51. Berkowitz SA, Seligman HK, Rigdon J, Meigs JB, Basu S. Supplemental Nutrition Assistance Program (SNAP) Participation and Health
52. Davis LL, Kyriakides TC, Suris AM, Ottomanelli LA, Mueller L, Parker PE, et al. Effect of Evidence-Based Supported Employment vs Transitional Work on Achieving Steady Work Among Veterans With Posttraumatic Stress Disorder: A Randomized Clinical Trial. JAMA Psychiatry. 2018;75(4):316-24.

53. Robert Wood Johnson Foundation. 2013;Pages https://www.rwjf.org/ content/dam/farm/reports/issue_briefs/2013/rwjf403360 on 12/30 2018.

Publisher's Note Springer Nature remains neutral with regard to jurisdictional claims in published maps and institutional affiliations. 